\title{
Population Genetic Studies of Tree Populations in the Neotropics
}

\author{
BERND DEGEN \\ Bundesforschungsanstalt für Forst- und Holzwirtschaft (BFH), \\ Institut für Forstgenetik und Forstpflanzenzüchtung, Sieker Landstrasse 2, D-22927 Grosshansdorf, Germany, \\ E-mail: b.degen@holz.uni-hamburg.de
}

Since the early fifties, forest geneticists have established provenance tests and accumulated data on population differentiation for phenotypic traits in tree populations from around the globe. This information was later complemented by numerous surveys of genetic diversity using gene markers, principally morphological traits and isozymes. A large body of experimental evidence documenting genetic organization has been accumulated for temperate trees. Over the past 20 years, similar efforts have been extended to populations of woody species in the tropics. Most of these studies have been conducted in the neotropics.

In face of rapid deforestation in the tropics a central question is: what is the relative contribution of evolutionary history, logging, forest fragmentation, genetic processes, and demographic phenomena to diversity and genetic structure in the tree populations? In classical population genetics, these issues have been investigated through theoretical work using simplified scenarios. More recently, new techniques and methods have been developed which are now contributing in novel and important ways to our understanding of the evolution of genetic diversity in tropical tree populations. First, computer simulations have been developed and are now routinely used to analyse the dynamics of genetic structure and to test hypotheses about the impact and function of specific processes. Second, new protocols have been developed to enable DNA-extraction for genetic inventories from trunk cambium. Thus rapid sampling of large numbers of trees have become feasible even in high density tropical forests where the access to leaves in the crown is complicated. Third, new genetic markers have become available for many tropical tree species that have opened doors and made it possible to address new and complicated questions within populations. Chloroplast DNA polymorphisms offer a tool for tracking fruit dispersal and for investigating the continuity of maternal lineages in tree populations. AFLP-markers offer the possibility to screen the genetic variation at up to a few hundred loci. Thus former limitations due to small number of sampled loci can be overcome. Microsatellite markers have provided the high levels of polymorphism we need to reconstruct, in detail, mating patterns within a study area. And new techniques and tools are continuously developed, which will offer us even more powerful methods for understanding and for documenting the ways in which elements of evolutionary history, logging and forest fragmentation and ecological processes interact to structure tropical tree populations.

In this special issue of Silvae Genetica, we present a group of six papers focusing on aspects of neotropical population genetics. Five of the six assembled papers are the culmination of collaborative work between Latin American and European scientists (from Belgium, Brazil, Costa Rica, France, French Guiana, Germany, Panama, United Kingdom) and funded by a series of EU projects in conjunction with national partner grants (through the INCO-DEV programmes in frameworks 3, 4 and 5, and including the project GENEO-TROPECO). The other paper is the collaborative output of researchers from Canada and Brazil working on the DENDROGENE-project. The Dendrogene Project was part of the environmental cooperation programme of the Brazilian and British governments with the objective to elaborate recommendations for the "Genetic Conservation within managed Forest in Amazônia”. 